\title{
Spatio-temporal evolution and improvement po- tential of agricultural eco-efficiency in Jiangsu Province
}

\author{
Zaijun $\mathrm{Li}^{1}$,Meijuan $\mathrm{Hu}^{2}$, and Tao Jin ${ }^{3 *}$
}

\author{
1. Research Institute of Central Jiangsu Development, Yangzhou University, \\ Yangzhou 225009, China. junzailinyi@gmail.com \\ 2. School of Tourism and Culinary Science, Yangzhou University, Yangzhou \\ 225127, China. humeijuan156@163.com \\ 3. Jiangsu Co-Innovation Center for Modern Production Technology of \\ Grain Crops, Yangzhou University, Yangzhou 225009, China. tjin@yzu.edu.cn
}

\begin{abstract}
Achieving eco-efficiency in agriculture production at low environmental costs is key to sustainable agriculture. Using the DEA-SBM model, this study evaluated the agricultural eco-efficiency of the 77 counties and districts in China's Jiangsu province from 1999 to 2018 and analyzed its spatio-temporal evolution pattern and influencing factors. The mains conclusions were as follows: (1) The overall agricultural eco-efficiency and its decomposition terms, pure technology efficiency and scale efficiency, exhibited a fluctuating downward trend. The regional inequality in agricultural eco-efficiency had been widening and exhibited a strong positive spatial association. (2) The agricultural eco-efficiency in Jiangsu province presented a "high south and low north" spatial pattern. High-level agricultural eco-efficiency areas were in the Taihu Plain in Sunan, while low-level agricultural eco-efficiency zones are distributed across Subei City. The High-High-type spatial association pattern is concentrated in the Suzhou-Wuxi-Changzhou region, while the Low-Low areas are mainly in the coastal regions of Subei and Suzhong. (3) The spatial pattern of PTE and SE generally exhibited a "high south and low north" distribution. Areas with positive growth in agricultural eco-efficiency, PTE, and SE, were situated in Xuzhou, Nanjing city, and the bordering regions between Yangzhou and Huai'an, and Changzhou and Wuxi. (4) The excessive redundant use and application of pesticides, chemical fertilizer, agricultural diesel, labor, land, and agricultural carbon emission have been the primary factor affecting Jiangsu's agricultural eco-efficiency. Irrigation had also signficantly impacted agricultural eco-efficiency, while mechanical power and agricultural film had minimal effect. The majority of counties and districts in Subei, Suzhong, and Ningzhen Yang Hilly region have issues regarding their excessive usage of chemical fertilizer, pesticide, chemical fertilizer, agricultural diesel, labor, and land. The findings of this study can contribute towards a better understanding of agricultural eco-efficiency and spatial association effect and can help policymakers increase agricultural eco-efficiency.
\end{abstract}


Keywords: agricultural eco-efficiency; DEA-SBM model; spatio-temporal evolution pattern; improvement potential; Jiangsu Province

\section{Introduction}

With rapid developments in China's agricultural industry, serious agriculture pollution, caused by the massive application of chemical fertilizer, agricultural plastics films, and pesticides linked to intensive agriculture growth patterns, is threatening sustainable agricultural development [1,2]. For instance, Jiangsu, one of China's primary agricultural production bases, remains in the conventional development mode of high investment, high consumption, and high output. In recent years, aimed at promoting agricultural yield, the province has declined into high material inputs, high carbon emissions, and low efficiency [3-5], which has resulted in increased discharges of agricultural $\mathrm{NH} 3$, Nitrogen, $\mathrm{CO}_{2}$, and chemical oxygen demand (COD), total nitrogen, and total phosphorus emissions [6-8]. These agricultural production byproducts have exerted significant adverse pollution spillovers on the soil, water, air, and neurobehavioral functions $[9,10]$. These phenomenon is opposite the goals of sustainable agriculture, which is aimed at conserving land and water resources, using environmentally non-degrading production techniques, and employing technically appropriate, economically, viable, and socially acceptable farming operations [11,12]. Hence, identifying green agricultural performance and its underlying influencing factors is crucial to ensuring the agricultural transformation and development of Jiangsu province from quantitative growth towards green and efficient development.

Eco-efficiency is considered an effective tool for measuring agricultural sustainability, linking the economic value of agricultural activities with its impact on the environment. Eco-efficiency is defined as the effectiveness of producing maximum economic output while consuming minimal natural resources and constraining environmental degradation $[13,14]$. The term is extended to the field of agriculture [12,15], coining the term agricultural eco-efficiency. While there is no universally accepted definition for agricultural eco-efficiency, the core aim of agricultural eco-efficiency is to produce more quantity and higher quality agricultural products and services using fewer natural resources and with minimal adverse effects on the environment. Increasing agricultural eco-efficiency would mean improving farm product quality (food safety and issue), lowering carbon emission, and enhancing resource utilization [16]. Agriculture eco-efficiency has been applied at various scales, from the national level [1,17], provincial level [18], city level [19], village level [20], up to the farm level [21,22]. However, based on our review of previous studies, little research has been conducted evaluating agricultural eco-efficiency at the county level, particularly in Jiangsu province. County is considered as the basic administrative unit in agricultural production management, and county agriculture constitutes the foundation of the national economy. 
Numerous methods have been applied to evaluate agricultural eco-efficiency, including the ratio method, life cycle accounting (LCA), ecological footprint, environmental sustainable value (ESV), stochastic frontier analysis (SFA), and data envelopment analysis (DEA) [23,24]. Some studies have found that nonparametric DEA is more applicable in evaluating agricultural eco-efficiency $[25,26]$. The advantage of DEA is that it avoids setting specific functional forms and deals with the efficiency problem of multi-input and multi-output system [27]. Various improvements have been proposed to improve on the limitations of the traditional DEA. For example, Tone [28] proposed the non-radial slacks-based measure (SBM) of efficiency in DEA, which resolves the slack of input excesses and the output shortfalls and measures the inefficiency of the decision making units (DMU) in traditional DEA. Tone [29] further extended the SBM to consider undesirable outputs for production efficiency evaluation. Hence, the SBM model that incorporates slack variables and undesirable outputs can better reflect the nature of eco-efficiency evaluation [30].

The first law of geography posits that everything is related to everything else and that near things are more related than distant things [31]. Similarly, space is highly consequential in environmental and resource economic analyses [32]. Spatial effects concerning spatial dependence, heterogeneity, and clustering have been considered in energy eco-efficiency [33,34], and regional eco-efficiency [35]. The spatial effect of inter-regional eco-efficiency can be evaluated by measuring the global and local Moran's I. For Jiangsu, the agricultural zone can be divided into six types according to the physiographic and socioeconomic composition of the province: (1) Taihu lake agriculture area, (2) the agriculture area along the Yangtze River, (3) Ningzheny Yang hilly agricultural area, (4) Xuzhou-Huai'an agriculture area, (5) the coastal agriculture area, and (6) Lixiahe river area. Given similar production conditions, this study explores the spatial dimension of agricultural eco-efficiency and analyzes local spatial clustering of agricultural eco-efficiency in Jiangsu province. Scientific evaluation of the spatio-temporal evolution characteristics of agricultural eco-efficiency can support the development and implementation of high-quality green agricultural strategies.

In this study, the DEA-SBM model was used to assess the agricultural eco-efficiency in Jiangsu's 77 counties and districts from 1999 to 2018 and incorporated agricultural carbon emissions in the analysis. The main research questions of the study are as follows: (1) What is the temporal variation trend in agricultural eco-efficiency and its decomposition contribution term in Jiangsu province for the study period? (2) What are the spatial differences in agricultural eco-efficiency based on characteristics, association patterns, and growth type? (3) What are the primary sources of agricultural eco-efficiency loss for the various counties and districts?

\section{Materials and Methods}

\subsection{Study Area}

Jiangsu province is located on the developed eastern coast of China, situated at the lower reaches of the Yangtze and Huaihe Rivers. The terrain is covered by vast plain and water areas with patches of mountains and hilly lands. Due to rapid urbanization and industrialization, losses in croplands have continued, decreasing from $700.10\left(10^{\wedge} 4 \mathrm{hm} 2\right)$ in 2000 to $633.06\left(10^{\wedge} 4 \mathrm{hm} 2\right)$ in 2015 [36]. The per capita cultivated land is $0.85 \mathrm{mu}$, equivalent to two-thirds of the national average. In southern Jiangsu, the value difference is even more pronounced with the per capita cultivated land less than $0.3 \mathrm{mu}$. Due to the region's limited per capita arable land and dense population, Jiangsu's agricultural production is highly dependent on ferti- 
lizer usage, resulting in high carbon emission and intensified environmental pressures [37].

Jiangsu is one of the 13 major grain-producing provinces in China. Its grain production experienced a cyclical fluctuation from high to low to high, from 1999 to 2018. Adjustments in the agricultural structure started in 1999, after years of declining grain yield. A series of food production support policies were implemented (e.g., seed, fertilizer, and machinery subsidies, lowest grain purchase, and infusion of agricultural capital) that resulted in the increased grain production over consecutive harvest years.

Jiangsu is located in the northern wing of the Yangtze River Delta economic zone. Jiangsu is composed of 13 municipalities, which can be further subdivided into three regions based on the socioeconomic boundaries: Subei, Suzhong, and Sunan. The level of economic development varies greatly among the three regions, decreasing from south to north. The proximity of Shanghai likely influences this difference in economic levels resulting in regional agricultural clusters.

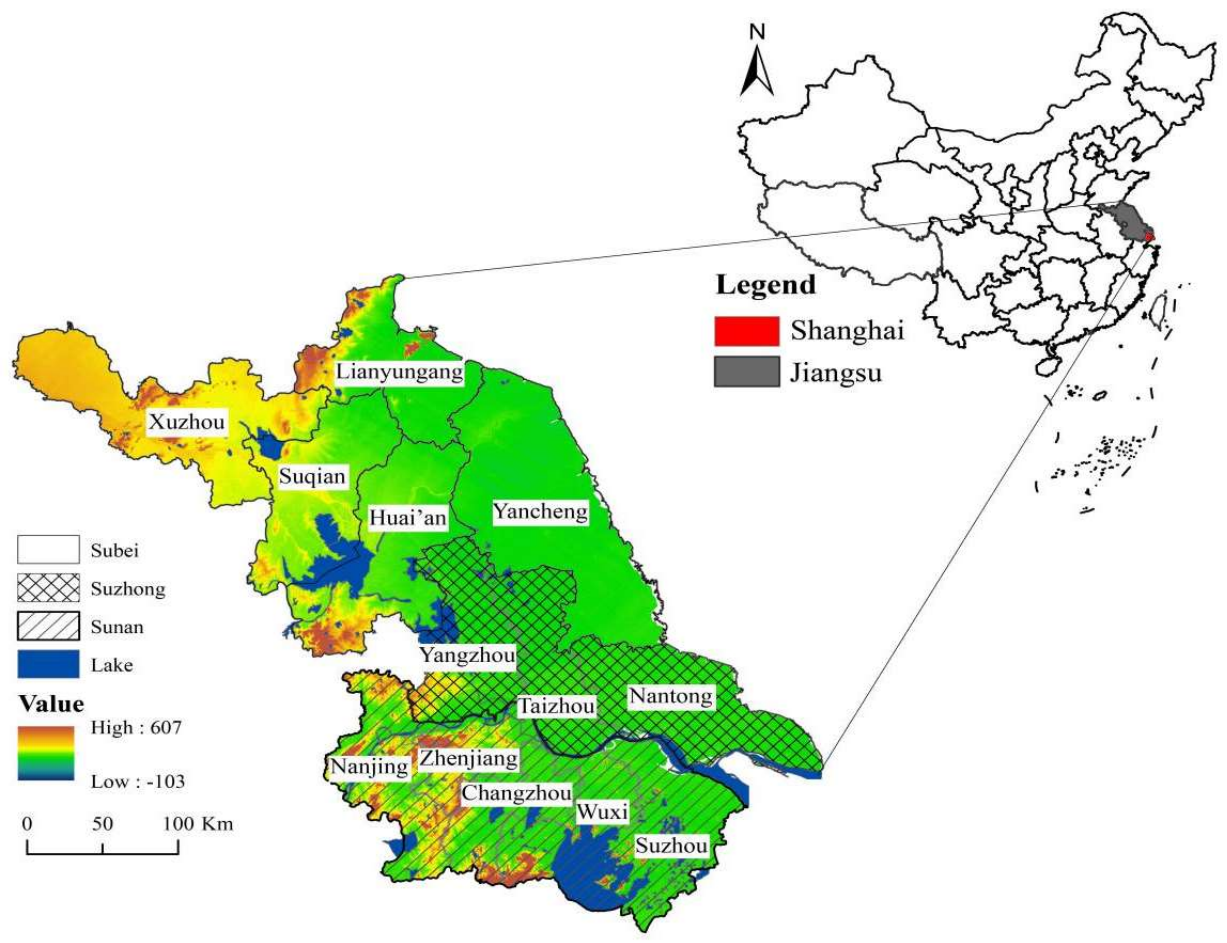

Figure 1. The study area

\subsection{Methods}

\subsubsection{DEA-SBM}

Research manuscripts reporting large datasets that are deposited in a publicly available database should specify where the data have been deposited and provide the relevant accession numbers. If the accession numbers have not yet been obtained at the time of submission, please state that they will be provided during review. They must be provided prior to publication. 
As a non-radial and non-oriented DEA model, the SBM model has the advantage of settling the problem of input and output slacks and avoid radial and oriented deviation. In this study, we selected the 77 counties of Jiangsu as the DMUs. Each unit contains input, desirable outputs, and undesirable outputs (carbon emission), represented by the vectors: $x \in R^{m}, y_{g} \in R^{s_{1}}, y_{b} \in R^{s_{2}}$, respectively. The matrices $X \quad Y_{g}$ and $Y_{b}$ are defined as follows [38,39]:

The agricultural eco-efficiency, including undesirable outputs, can be calculated as follows:

$$
[\mathrm{SBM}] \quad \rho^{*}=\min \frac{1-\frac{1}{m} \sum_{i=1}^{m} \frac{s_{i}^{-}}{x_{i 0}}}{1+\frac{1}{s_{1}+s_{2}}\left(\sum_{r=1}^{s_{1}} \frac{s_{r}^{g}}{y_{r 0}^{g}}+\sum_{r=1}^{s_{2}} \frac{s_{r}^{b}}{y_{r 0}^{b}}\right)}
$$

where $s^{-} \in R^{m}, s^{g} \in R^{s_{1}}$, and $s^{b} \in R^{s_{2}}$ represent the slacks in inputs, desirable outputs, and undesirable outputs; and m, s1, and s2 indicate the number of factors for inputs, desirable outputs, and undesirable outputs. When there is no superfluous input, insufficient desirable output, and redundant undesirable output (i.e., $\left.s^{-}=0, s^{g}=0, s^{b}=0\right)$, the DMU0 $\left(x_{0}, y_{g 0}, y_{b 0}\right)$ is efficient. However, if the DMU0 is inefficient, the inputs, desirable outputs, and undesirable outputs would have to be improved. The vectors $s^{-}$indicates that the actual input resource is more than the frontier input. $s^{g}$ indicates whether the desirable output produced in the realistic operation is less than the frontier desirable output. $s^{b}$ means that the actual undesirable output level is greater than the leading edge of the undesirable output level. $\lambda$ is the intensity vector.

The agricultural eco-efficiency (OE) can be decomposed into pure technical efficiency (PTE) [40], and scale efficiency (SE). PTE refers to the efficiency of resource allocation, utilization and pollution control, management, and production technology. SE refers to the efficiency of the resource scale, determining whether the DMUs are at optimal production scale [30]. The value $\rho^{*}$ is between 0 and 1 . If $\rho^{*}=1$, the eco-efficiency of DMU0 is said to be efficient, and PTE and SE are also efficient. If $\rho^{*}<1$, the DMU0 is considered to be inefficient, and PTE or SE is inefficient but can be improved by deleting the excess in bad outputs and augmenting the shortfalls in good outputs via the SBM-projection [41]. In this study, the agri- 
cultural eco-efficiency, PTE, and SE for each county and district in Jiangsu were calculated using MaxDEA Ultra 8.8 Software from 1999 to 2017.

\subsubsection{Gini coefficient and variation coefficient (CV)}

The degree of inequality in agricultural eco-efficiency can be measured by the coefficient of variation $(\mathrm{CV})$ and the Gini coefficient.

$$
\begin{aligned}
& C V=s / \bar{x} \\
& \text { Gini }=\frac{1}{2 n^{2} \bar{x}} \sum_{i=1}^{n} \sum_{i=1}^{n}\left|X_{i}-X_{j}\right| \\
& \text { where } \bar{x}=\sum_{i=1}^{n} X_{i} / 77, s=\sqrt{(1 / 76) \sum_{i=1}^{n}\left(X_{i}-\bar{x}\right)}, \mathrm{n} \text { is the number of counties }
\end{aligned}
$$

and districts, and $X_{i}$ denotes the specific agricultural eco-efficiency in the i counties and districts.

\subsubsection{Exploratory Spatial Data Analysis (ESDA)}

ESDA is a set of synthesized methods specialized in exploring spatial distributions and identifying spatial association, clusters, and hot (or cold) spots, for both global and local spatial autocorrelations [42,43]. The global Moran's I is mostly used to describe the global spatial autocorrelation, and is defined for $\mathrm{n}$ observations on an attribution variable $x$ as follows [44]:

$$
I=\frac{n}{S_{0}} \frac{\sum_{i=1}^{n} \sum_{j=1}^{n} w_{i j}\left(x_{i}-\bar{x}\right)\left(x_{j}-\bar{x}\right)}{\sum_{i=1}^{n}\left(x_{i}-\bar{x}\right)^{2}}
$$

where $x_{i}$ and $x_{j}$ are the agricultural eco-efficiency value for units $\mathrm{i}$ and $\mathrm{j}$; $\bar{x}$ is the mean of variable $\mathrm{x} ; w_{i j}$ is the defined spatial queen matrix; and $S_{0}=\sum_{i=1}^{n} \sum_{j=1}^{n} w_{i j}$. The $\mathrm{Z}$ score can be calculated to determine whether significant spatial autocorrelation exists. A Moran's I index value close to 1 indicates positive spatial clustering, while a value close to 0 indicates random distribution.

While global spatial autocorrelation can establish whether spatial clustering exists, it is unable to determine where the spatial clustering occurs. Local spatial 
autocorrelation can be used to explain the patterns of local clustering. For provinces $i$ and year $t$, the local spatial autocorrelation is expressed as [45]:

$$
I_{i}=\left(\frac{x_{i}}{m_{0}}\right) \sum_{j=1}^{n} w_{i j} x_{j} \text { with } m_{0}=\sum_{i=1}^{n} \frac{x_{i}^{2}}{n}
$$

Four types of spatial association can be identified based on the value of adjacent regions from the local spatial autocorrelation: High-High, Low-Low, High-Low, and Low-High. Regions classified as High-High, are those with greater-than-average values clustered in areas with greater-than-average values. Similarly, Low-Low, High-Low, and Low-High clusters can be defined. Only the High-High and Low-Low classes represent positive spatial autocorrelation since these categories have similarly valued regions clustered together.

\subsection{Data source}

General agriculture comprises agriculture, forestry, animal husbandry, and fishery, while special agriculture only refers to planting. Planting is the foundation of agriculture and is the most important component of agricultural eco-efficiency. In this study, special agriculture (i.e., planting) is selected as the research object to measure agricultural eco-efficiency. Using available data from the Jiangsu's Statistics Bureau, seven input indicators were selected, characterizing agricultural labor, land, irrigation, chemical fertilizer, and pesticide usage. Both desirable and undesirable output indicators were included, and the evaluation system for the input-output and variable selection is described in Table 1.

Agriculture carbon emission was incorporated as undesirable agricultural output. The main carbon sources for agriculture production activities were identified as chemical fertilizer, pesticide, film, diesel, irrigation, and tillage. Based on existing studies $[4,20,46]$, the values used for the emission coefficients are as follows: agricultural chemical fertilizer $(0.8956(t / t))$, agricultural pesticide $(4.9341$ $(t / t))$, agricultural film $(5.18(t / t))$, agricultural diesel $(0.5927(t / t))$, agricultural irrigation $(0.26648(\mathrm{t} / \mathrm{hm} 2)$, and arable land $(0.3126(\mathrm{t} / \mathrm{hm} 2))$.The agricultural expected output indicators were characterized using the total agricultural output value. Price data were adjusted to 1999 prices to eliminate the impact of price fluctuations. All data were collected from the Jiangsu Statistical Yearbook (2000-2018) and the Rural Statistical Yearbook of Jiangsu Province (2000-2018), published annually by the Jiangsu Statistics Press.

Table 1. The evaluation indicators of agricultural eco-efficiency

\begin{tabular}{lccccccc}
\hline Primary indices & $\begin{array}{c}\text { Secondary Indi- } \\
\text { ces }\end{array}$ & Interpretation & Max & Min & Mean & Stdev & Number \\
\hline \multirow{2}{*}{ Input indicators } & $\begin{array}{c}\text { Mechanical } \\
\text { power }(\mathrm{x} 1)\end{array}$ & $\begin{array}{c}\text { Total agricultural machinery } \\
\text { power }\left(10^{\wedge} 4 \mathrm{kw} \cdot \mathrm{h}\right)\end{array}$ & 501 & 0.24 & 11.24 & 15.35 & 1463
\end{tabular}




\begin{tabular}{|c|c|c|c|c|c|c|c|}
\hline & Irrigation (x2) & $\begin{array}{l}\text { Effective irrigation area } \\
\qquad\left(10^{\wedge} 3 \mathrm{hm}^{2}\right)\end{array}$ & 253.58 & 0.55 & 100.13 & 61.53 & 1463 \\
\hline & Labor (x3) & $\begin{array}{l}\text { Agricultural practitioner (Mil- } \\
\text { lion person) }\end{array}$ & 159.29 & 3.75 & 50.33 & 27.86 & 1463 \\
\hline & Land (x4) & $\begin{array}{l}\text { Cultivated land area } \\
\qquad\left(10^{\wedge} 3 \mathrm{hm}^{2}\right)\end{array}$ & 211.67 & 2.44 & 48.57 & 31.09 & 1463 \\
\hline & Pesticide (x5) & Usage of pesticides (ton) & 152481 & 1755 & 43222.07 & 32454.57 & 1463 \\
\hline & $\begin{array}{l}\text { Agricultural film } \\
\qquad(\mathrm{x} 6)\end{array}$ & $\begin{array}{l}\text { Usage of plastic sheeting } \\
\text { (ton) }\end{array}$ & 15557 & 20 & 1156.64 & 859.61 & 1463 \\
\hline & $\begin{array}{l}\text { Chemical ferti- } \\
\text { lizer }(x 7)\end{array}$ & Usage of fertilizers (ton) & 10230 & 39 & 1160.99 & 1274.16 & 1463 \\
\hline & Diesel (x8) & Usage of diesel oil (ton) & 79125 & 355 & 11696.16 & 13131.94 & 1463 \\
\hline $\begin{array}{l}\text { Expected output } \\
\text { indicator }\end{array}$ & $\begin{array}{l}\text { Carbon emission } \\
\text { (z1) }\end{array}$ & $\begin{array}{l}\text { Agricultural carbon emissions } \\
\text { (ton) }\end{array}$ & 18.88 & 0.38 & 5.88 & 4.06 & 1463 \\
\hline $\begin{array}{l}\text { Undesirable output } \\
\text { indicator }\end{array}$ & $\begin{array}{l}\text { Output value } \\
\text { (z2) }\end{array}$ & $\begin{array}{l}\text { Total gross output value of } \\
\text { agriculture (billion) }\end{array}$ & \multicolumn{5}{|c|}{160122210757273295.09209448 .06} \\
\hline
\end{tabular}

\section{Results}

\subsection{Temporal evolution pattern of regional agricultural eco-efficiency}

After calculating the geometric mean value of the agricultural eco-efficiency, the pure technical and the scale efficiencies for all of Jiangsu's counties and districts were calculated from 1999 to 2018. The temporal change in agricultural eco-efficiency was then plotted and is presented in Figure 2.

As shown in the graph (Figure 2), the annual mean agricultural eco-efficiency was 0.640 , which means that the actual input is only about $64.0 \%$ of the optimal input. Under constant output, the reduction of $36.0 \%$ of input would achieve effective agricultural eco-efficiency. The geometric mean value for the annual PTE was 0.730 , while the was 0.876 . Both values are above the annual mean value of agricultural eco-efficiency, and the value of SE was greater than PTE.

The graph (Figure 2) also shows that agricultural eco-efficiency exhibited a generally downward fluctuating trend. From 0.669 in 1999, the value increased to 0.695 in 2002, dropped to 0.597 in 2003, rose to the peak value of 0.741 in 2006, declined to 0.574 in 2011, and then rebounded to 0.621 in 2018. The temporal pattern of PTE exhibited a consistent fluctuation trend in agricultural eco-efficiency. For the SE, the value rose from 0.867 in 1999 to 0.933 in 2006 and declined to 0.879 in 2018. Its contribution rate to agricultural eco-efficiency increased from $129.65 \%$ in 1999 to $141.55 \%$ in 2018. 


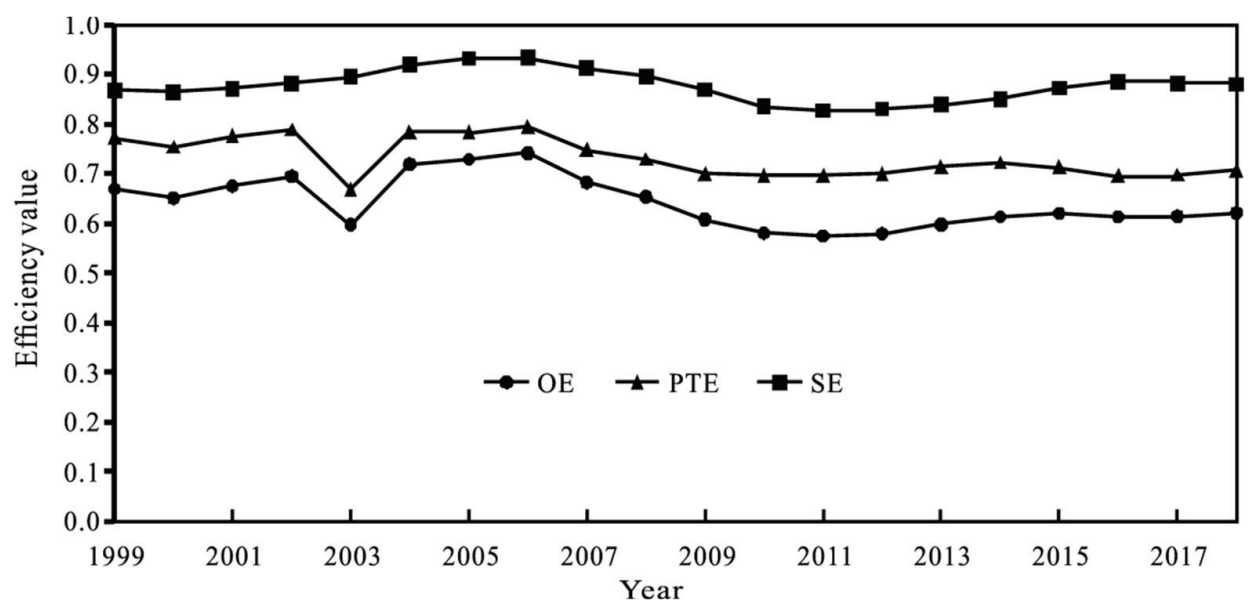

Figure 2. Temporal change in agricultural eco-efficiency from 1999 to 2018

\subsection{Spatial evolution pattern of agricultural eco-efficiency}

To examine the spatial differentiation patterns of agricultural eco-efficiency, the coefficient variation (CV) and Gini values of regional agricultural eco-efficiency were calculated. ArcGIS 10.5 software was used to analyze and calculate the annual geometric mean value and the spatial variation coefficient of agricultural eco-efficiency for each county and district. Using 0.65 to divide the spatially high and low agricultural eco-efficiencies, and using 0.19 to separate relative equality and inequality groups, the spatial and temporal groupings of agricultural eco-efficiency was obtained.

As shown in Figure 3, the CV and Gini values of agricultural eco-efficiency showed a fluctuating but generally, upward trend, experiencing an initial decline followed by a strong, rising trend. Specifically, the CV and Gini values decreased from 0.239 and 0.132 in 1999, to 0.195 and 0.110 in 2004, and rose to 0.332 and 0.190 in 2018. These trends indicate that in recent years, the regional difference in agricultural eco-efficiency leaned towards expansion.

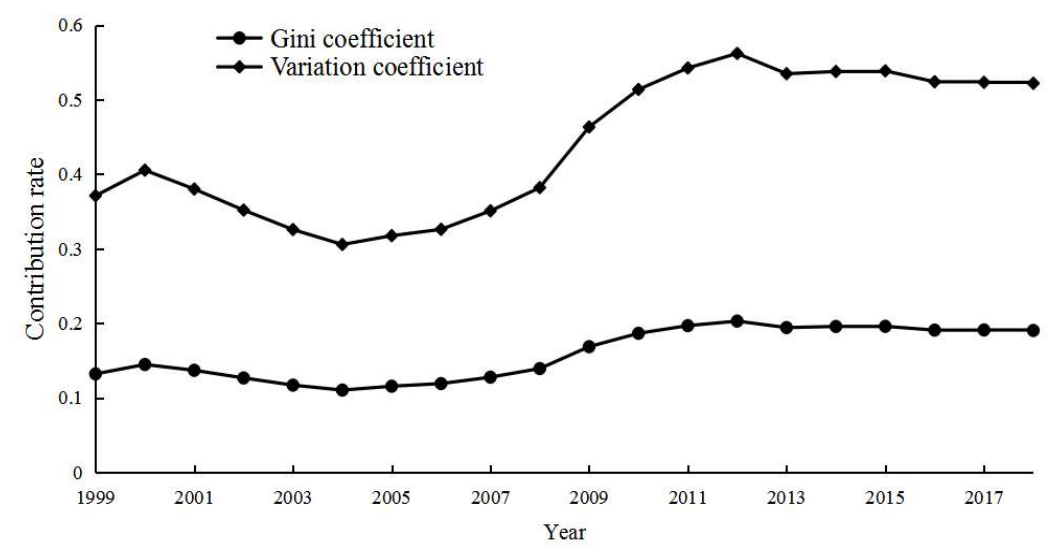

Figure 3. The CV and Gini coefficient of regional agricultural eco-efficiency from 1999 to 2018

As shown in Figure 4, the agricultural eco-efficiency in Jiangsu province as a whole presented a "high south and low north" distribution pattern. Counties and 
districts with high agricultural eco-efficiency values were situated mainly around the Taihu Plain in Sunan and scattered in Nanjing, Yangzhou, Huai'an, and Taizhou City. Those with the low agricultural eco-efficiency were mainly located in Subei, particularly along the coasts, and in Ningzhen Yang Hilly of Sunan.

The variation coefficient for each county and district was also computed from 1999 to 2018 to identify inter-annual fluctuation patterns. Overall, the variation coefficient ranged from 0.074 to 0.408 , which suggests a large interannual difference in agricultural eco-efficiency for most counties and districts. The spatial pattern of regional variation coefficient was largely the reverse of the calculated geometric mean of agricultural eco-efficiency. High variation coefficient regions were mainly found in Subei, particularly in Yancheng and Huai' an city, while low variation coefficient regions were mainly in Sunan and Suzhong. Regions with high geometric mean in agricultural eco-efficiency were found to more likely have little inter-annual variation. In contrast, regions with lower geometric mean were more likely to have large interannual fluctuations, indicating that the spatial evolution pattern of agricultural eco-efficiency has cumulative and inertia effects. Low agricultural eco-efficiency regions were more susceptible to input conditions in agricultural production.

The spatial combination type of high and low, equality and inequality agricultural eco-efficiency was generally consistent with the spatial pattern of agricultural eco-efficiency geometric mean. The high-and-equal type was mainly distributed in Sunan, Yangzhou in Suzhong, Dafeng county, and Huai'an districts, accounting for $32.47 \%$ of the entire region. The low-and-unequal and low-and-equal types were scattered in the Ningzhen Yang Hilly region and the northern and coastal counties in Subei, accounting for $50.65 \%$.

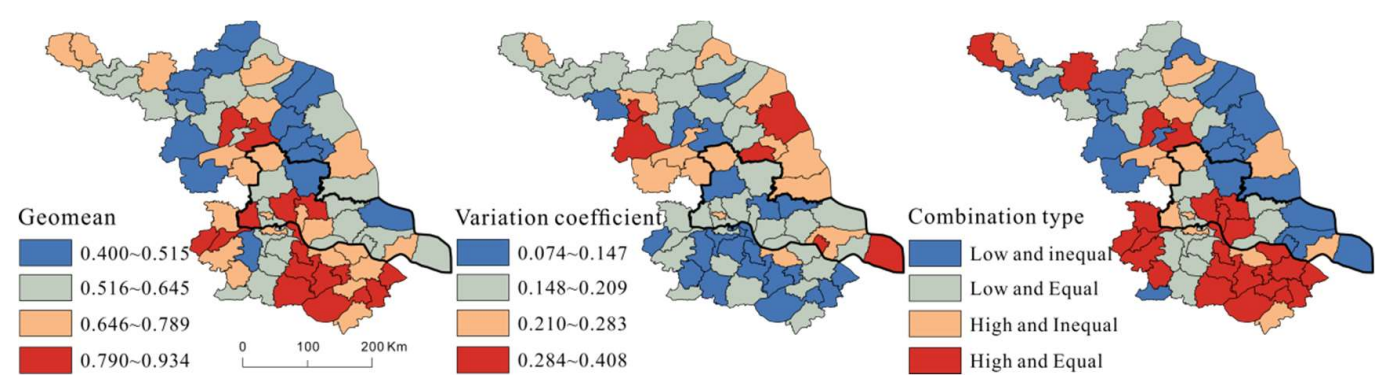

Figure 4. Spatial pattern of regional agricultural eco-efficiency

\subsection{Spatial association pattern of agricultural eco-efficiency}

The global Moran's I of agricultural eco-efficiency exhibited a positive spatial correlation. Overall, the global Moran's I passed the 5\% significance level except in 2003, 2004, and 2005, which suggests that Jiangsu's agricultural eco-efficiency had significant clustering and that the clustering degree showed a fluctuating and expanding trend. Similarly, the Moran's I of agricultural eco-efficiency fluctuated down to the lowest level in 2004, followed by a rapid increase. The results suggest a consistent variation trend between the value of the spatial association and re- 
gional difference in the agricultural eco-efficiency. With improving agricultural eco-efficiency in all counties and districts in 2000 and 2004, the regional difference and spatial clustering had been significantly reduced. However, the Moran's I value in regional agricultural eco-efficiency has since expanded since 2004.

Table 2. The Moran's I of agricultural eco-efficiency from 1999 to 2018

\begin{tabular}{cccccccc}
\hline Year & Moran's I & $\mathrm{Z}$ & $\mathrm{P}$ & Year & Moran's I & $\mathrm{Z}$ & $\mathrm{P}$ \\
\hline 1999 & 0.3372 & 4.696 & 0.000 & 2009 & 0.1875 & 2.680 & 0.004 \\
2000 & 0.3301 & 4.598 & 0.000 & 2010 & 0.1834 & 2.626 & 0.004 \\
2001 & 0.3225 & 4.490 & 0.000 & 2011 & 0.2628 & 3.685 & 0.000 \\
2002 & 0.3306 & 4.598 & 0.000 & 2012 & 0.2590 & 3.633 & 0.000 \\
2003 & 0.0269 & 0.538 & 0.295 & 2013 & 0.3249 & 4.512 & 0.000 \\
2004 & 0.0174 & 0.410 & 0.341 & 2014 & 0.3403 & 4.713 & 0.000 \\
2005 & 0.0448 & 0.774 & 0.219 & 2015 & 0.3541 & 4.898 & 0.000 \\
2006 & 0.1340 & 1.965 & 0.025 & 2016 & 0.3140 & 4.367 & 0.000 \\
2007 & 0.1539 & 2.232 & 0.013 & 2017 & 0.3821 & 5.275 & 0.000 \\
2008 & 0.1818 & 2.604 & 0.005 & 2018 & 0.2792 & 3.904 & 0.000 \\
\hline
\end{tabular}

Global Moran's I values do not reflect the spatial association characteristics of a particular region, and so, the local Moran's I value is used to explore the local clustering characteristics of agricultural eco-efficiency at five time periods: 1999, 2004, 2009, 2014, and 2018. According to the LISA agglomeration diagram (as shown in Figure 5), the local spatial correlation in Jiangsu's agricultural eco-efficiency shows the following characteristics: (1) The overall agricultural eco-efficiency presented a significant phenomenon of High-High and Low-Low spatial clusters, with the High-High type accounting for $32.47 \%$, and the Low-Low type accounting for $35.06 \%$. The rest (High-Low and Low-High agglomeration regions) only accounted for $32.47 \%$. (2) The spatial association pattern in regional agricultural eco-efficiency exhibited pronounced spatial variability. The High-High agglomeration regions showed significant spatial changes, with the initial clustering in the border regions of Wuxi, Nantong, and Suzhou city shifting to the districts of Nanjing and Taizhou city. The clustering then shifted towards the Suzhou-Wuxi-Changzhou region before expanding into high-level agricultural eco-efficiency areas of Xuzhou, Changzhou, and Nanjing City. The Low-Low agglomeration regions exhibited noticeable contraction with an initial scattered distribution among inland counties and districts of Xuzhou, Huai'an, and Nanjing City, shifting towards coastal counties and districts of Subei and Suzhong, especially in Yancheng and Nantong city and parts of Lianyungang and Suqian City. The High-Low and Low-High regions had unsta- 
ble spatial patterns; the number of High-Low regions decreased, while the Low-High regions clustered in the Ningzhen Yang Hilly mountain area.

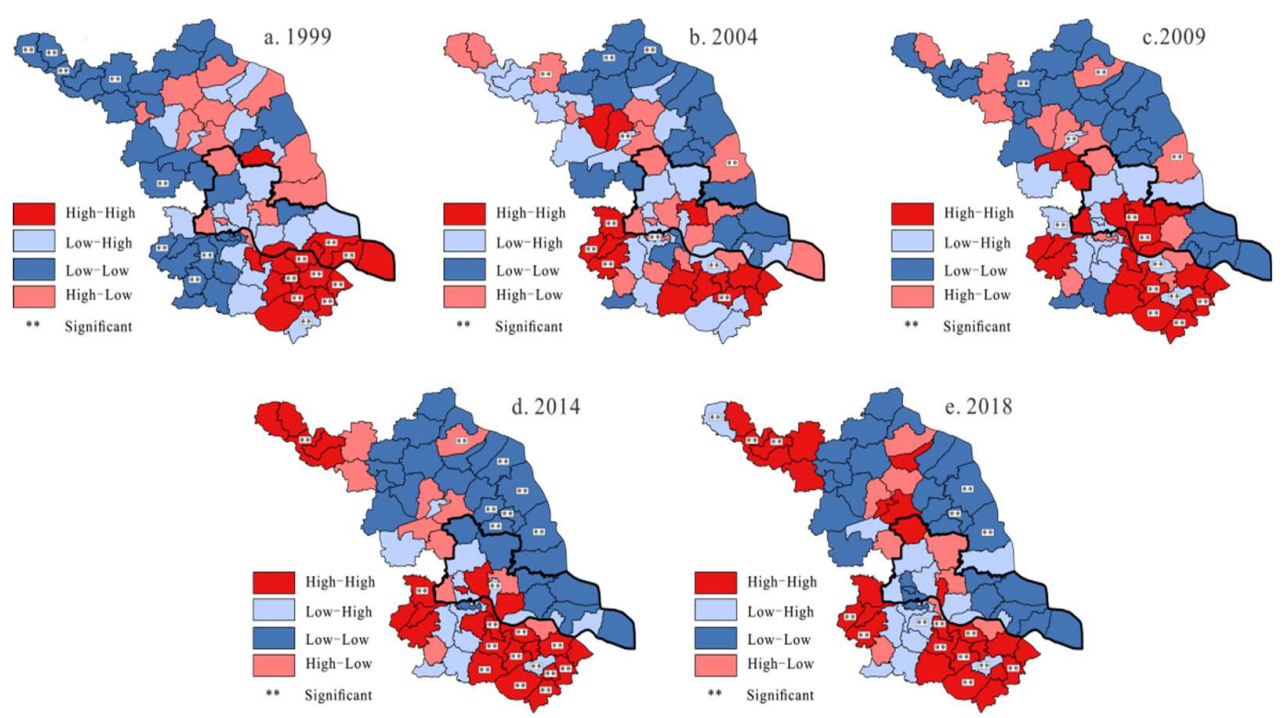

Figure 5. Spatial association pattern of regional agricultural eco-efficiency

\subsection{Spatial decomposition and growth pattern of agricultural eco-efficiency}

The growth coordination between agricultural eco-efficiency, PTE, and SE was identified, mapped, and categorized in terms of growth type. As shown in Figure 6, the spatial geomean pattern of PTE is generally consistent with agricultural eco-efficiency, where high values are found in the north, and low values are at the south. Regions with relatively low PTE geomean were distributed in Subei, the coastal regions of Suzhong, and parts of the Ningzhen Yang Hilly region. For SE, the geomean value for each county and district was higher than the PTE, indicating that SE contributed significantly in promoting agricultural eco-efficiency. The SE exhibited high south and low north spatial pattern. Areas with high SE were found mainly in Sunan, the inland regions of Suzhong, and Huai'an city of Subei, while low SE Regions were clustered in the coastal and northern regions of Subei, particularly in Yancheng city.

For the study period, areas with positive growth in TE, PTE, and SE accounted for $27.27 \%$ and were mainly situated in Xuzhou, Huai'an, Yangzhou, Nanjing, and Changzhou City. This suggests these regions' positive agricultural eco-efficiency growth had been accompanied by the synergistic growth in EC and TC. Areas with negative TE, negative PTE, and positive SE, accounted for $22.08 \%$ and were mainly distributed in the Subei region. Areas with this growth combination had their agricultural eco-efficiency growth dragged down by the lag in PTE growth. Areas with negative TE, PTE, and SE comprised about $25.97 \%$ and were concentrated in the coastal regions of Suzhong and Sunan and along the Yangtze River region. In these regions, the negative agricultural eco-efficiency was caused by the deteriora- 
tion in PTE and SE. The other growth types were relatively marginal and are scattered throughout the entire province.
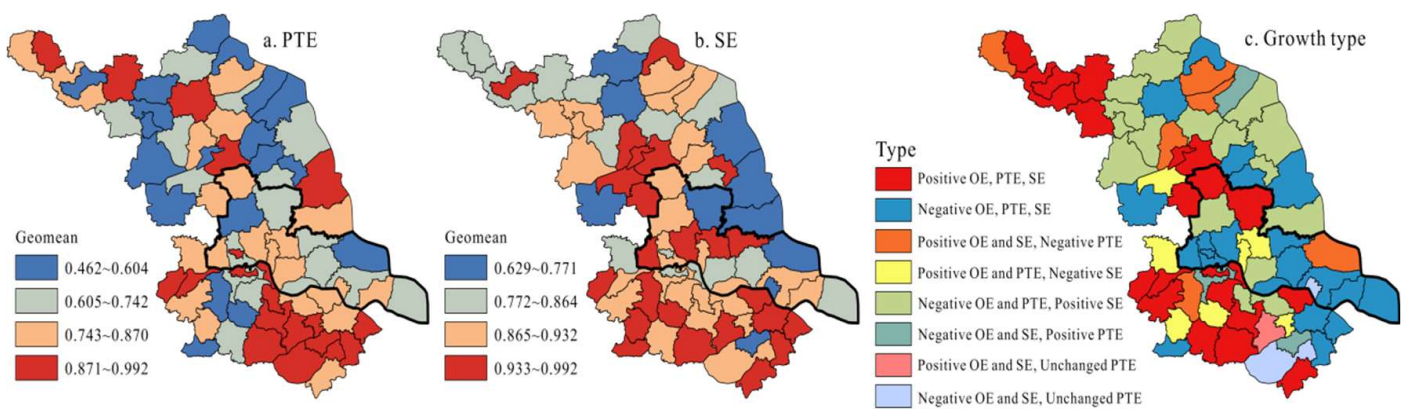

Figure 6. The geomean and growth type of between agricultural eco-efficiency, PTE, and SE

\subsection{The sources for agricultural eco-efficiency loss in Jiangsu province}

For the non-effective DEA unit, the results show that the input-output allocation had not reached the optimal level. The redundancy analysis of input factors can identify the reasons for agricultural eco-efficiency loss in Jiangsu province and clarify the potential for increasing agricultural eco-efficiency. According to the SBM model, when $\mathrm{p}^{*}<1, \mathrm{~s}^{-}, \mathrm{s}^{\mathrm{g}}$, and $\mathrm{s}^{\mathrm{b}}$ can reflect the redundancy of agricultural eco-efficiency. To calculate the input-output redundancy rate in each county or district, the redundancy value of each input indicator and undesirable output indicator is divide by each input indicator and undesirable output indicator. For analysis, the input-output redundancy rate can be subdivided into three categories: low value $(0-20 \%)$, moderate value $(20-35 \%)$, and high value $(>35 \%)$. The number and proportion of counties and districts for each indicator are shown in Table 3.

Table 3. The number and proportion of counties and districts at different intervals of indicators

\begin{tabular}{ccccccc}
\hline & \multicolumn{2}{c}{ Low Value } & \multicolumn{2}{c}{ Moderate Value } & \multicolumn{2}{c}{ High Value } \\
Type & Number & Proportion (\%) & Number & Proportion (\%) & Number & Proportion (\%) \\
\hline x1 & 24 & 31.17 & 34 & 44.16 & 19 & 24.68 \\
x2 & 19 & 24.68 & 35 & 45.45 & 23 & 29.87 \\
x3 & 16 & 20.78 & 24 & 31.17 & 37 & 48.05 \\
x4 & 14 & 18.18 & 26 & 33.77 & 37 & 48.05 \\
x5 & 9 & 11.69 & 15 & 19.48 & 53 & 68.83 \\
x6 & 28 & 36.36 & 30 & 38.96 & 19 & 24.68 \\
x7 & 11 & 14.29 & 12 & 15.58 & 54 & 70.13 \\
x8 & 15 & 19.48 & 20 & 25.97 & 42 & 54.55 \\
z1 & 9 & 11.69 & 16 & 20.78 & 52 & 67.53 \\
\hline
\end{tabular}


As shown in Table 2, the loss of agricultural eco-efficiency in most counties and districts resulted from the excessive use of pesticide (x5), chemical fertilizer $(x 7)$, diesel (x8), labor (x3), land (x4), and agricultural carbon emissions (z1). In particular, the number of counties and districts with high values of pesticide $(x 5)$ and chemical fertilizer (x7) use was 53 and 54, equivalent to $68.83 \%$ and $70.13 \%$. This means that about $68 \%$ of all counties and districts should reduce their agricultural pesticide and chemical fertilizer usage by at least 35\%. Similar conclusions are applicable for $x 8, x 3$, and $x 4$. In terms of the undesirable output (z1), $67.53 \%$ of all counties and districts were found to have high input-output redundancy rates. Since part of agricultural carbon emissions result from chemical fertilizer (x5), pesticide (x7), diesel (x8), and arable land (x4), excessive usage of agricultural chemicals and extensive farming techniques are significant factors influencing the agricultural eco-efficiency. Similarly, x2 exerted considerable effects on agricultural eco-efficiency, while x6 (32) and x1 (28) only had minimal effect.

ArcGIS 10.5 was then used to visualize the spatial difference of the reducible proportion for the different indicators. As shown in Figure 7, areas with high reducible proportions were mainly situated in Subei, Suzhong, and the Ningzhen Yang Hilly region, while the majority of low reducible proportion counties and districts were clustered in the Taihu plain. For chemical fertilizer (x7), the spatial pattern exhibited distinct south low and north high distribution. Similar spatial pattern could be drawn for $x 3, x 4, x 5$, and $x 8$. Due to improvements in agricultural mechanization and the growth of production technology, the improvement capabilities for $x 1, x 2$, and $x 6$ were limited in most counties and districts.
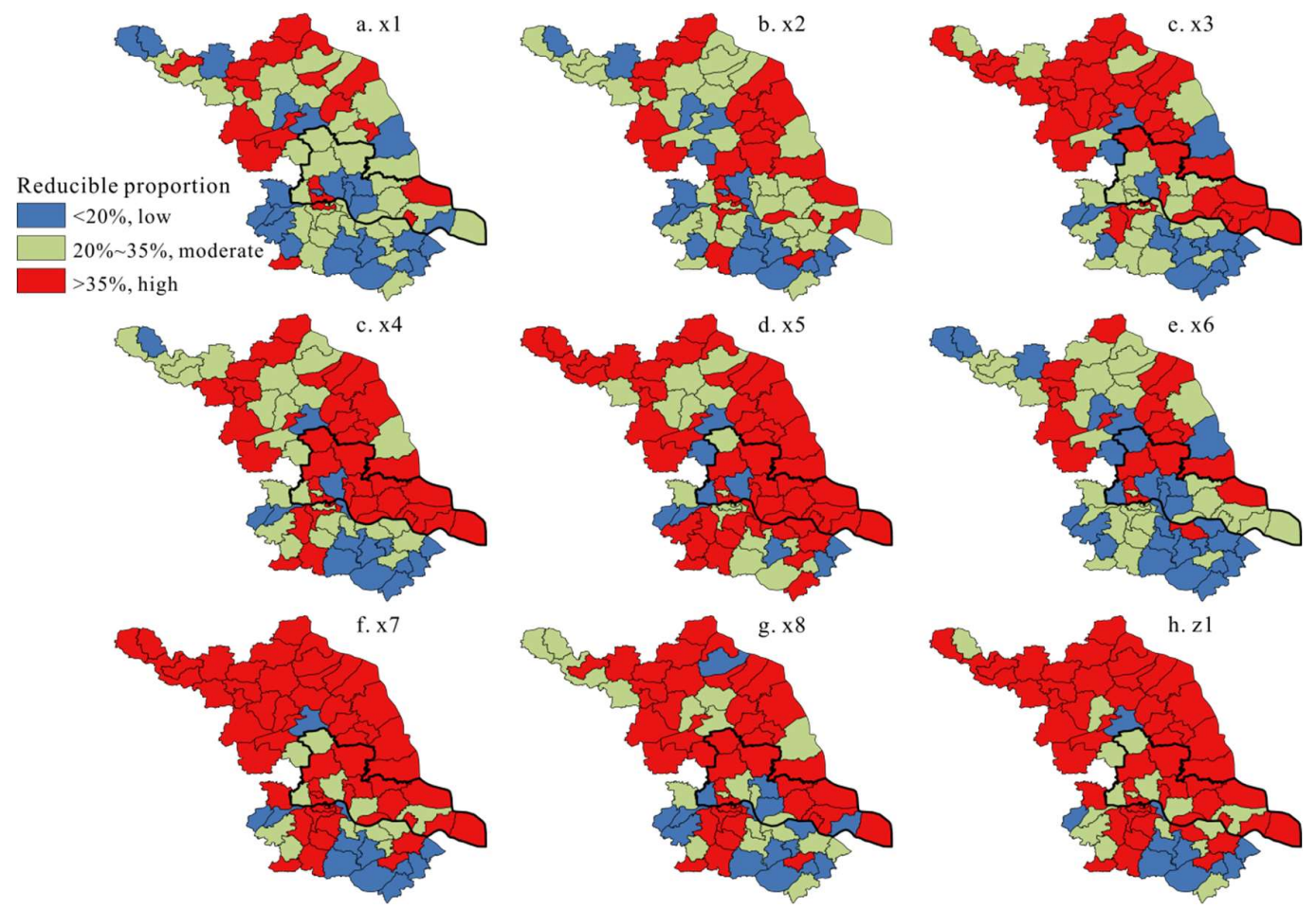

Figure 7.The improvement potential for agricultural ecological efficiency in Jiangsu province 
The Moran's I of agricultural eco-efficiency from 1999 to 2018

\begin{tabular}{cccccccc}
\hline Year & Moran's I & Z & P & Year & Moran's & Z & P \\
\hline 1999 & 0.3372 & 4.696 & 0.000 & 2009 & 0.1875 & 2.680 & 0.004 \\
2000 & 0.3301 & 4.598 & 0.000 & 2010 & 0.1834 & 2.626 & 0.004 \\
2001 & 0.3225 & 4.490 & 0.000 & 2011 & 0.2628 & 3.685 & 0.000 \\
2002 & 0.3306 & 4.598 & 0.000 & 2012 & 0.2590 & 3.633 & 0.000 \\
2003 & 0.0269 & 0.538 & 0.295 & 2013 & 0.3249 & 4.512 & 0.000 \\
2004 & 0.0174 & 0.410 & 0.341 & 2014 & 0.3403 & 4.713 & 0.000 \\
2005 & 0.0448 & 0.774 & 0.219 & 2015 & 0.3541 & 4.898 & 0.000 \\
2006 & 0.1340 & 1.965 & 0.025 & 2016 & 0.3140 & 4.367 & 0.000 \\
2007 & 0.1539 & 2.232 & 0.013 & 2017 & 0.3821 & 5.275 & 0.000 \\
2008 & 0.1818 & 2.604 & 0.005 & 2018 & 0.2792 & 3.904 & 0.000 \\
\hline
\end{tabular}

Global Moran's I values do not reflect the spatial association characteristics of a particular region, and so, the local Moran's I value is used to explore the local clustering characteristics of agricultural eco-efficiency at five time periods: 1999, 2004, 2009, 2014, and 2018. According to the LISA agglomeration diagram (as shown in Figure 5), the local spatial correlation in Jiangsu's agricultural eco-efficiency shows the following characteristics: (1) The overall agricultural eco-efficiency presented a significant phenomenon of High-High and Low-Low spatial clusters, with the High-High type accounting for $32.47 \%$, and the Low-Low type accounting for $35.06 \%$. The rest (High-Low and Low-High agglomeration regions) only accounted for $32.47 \%$. (2) The spatial association pattern in regional agricultural eco-efficiency exhibited pronounced spatial variability. The High-High agglomeration regions showed significant spatial changes, with the initial clustering in the border regions of Wuxi, Nantong, and Suzhou city shifting to the districts of Nanjing and Taizhou city. The clustering then shifted towards the Suzhou-Wuxi-Changzhou region before expanding into high-level agricultural eco-efficiency areas of Xuzhou, Changzhou, and Nanjing City. The Low-Low agglomeration regions exhibited noticeable contraction with an initial scattered distribution among inland counties and districts of Xuzhou, Huai'an, and Nanjing City, shifting towards coastal counties and districts of Subei and Suzhong, especially in Yancheng and Nantong city and parts of Lianyungang and Suqian City. The High-Low and Low-High regions had unstable spatial patterns; the number of High-Low regions decreased, while the Low-High regions clustered in the Ningzhen Yang Hilly mountain area. 

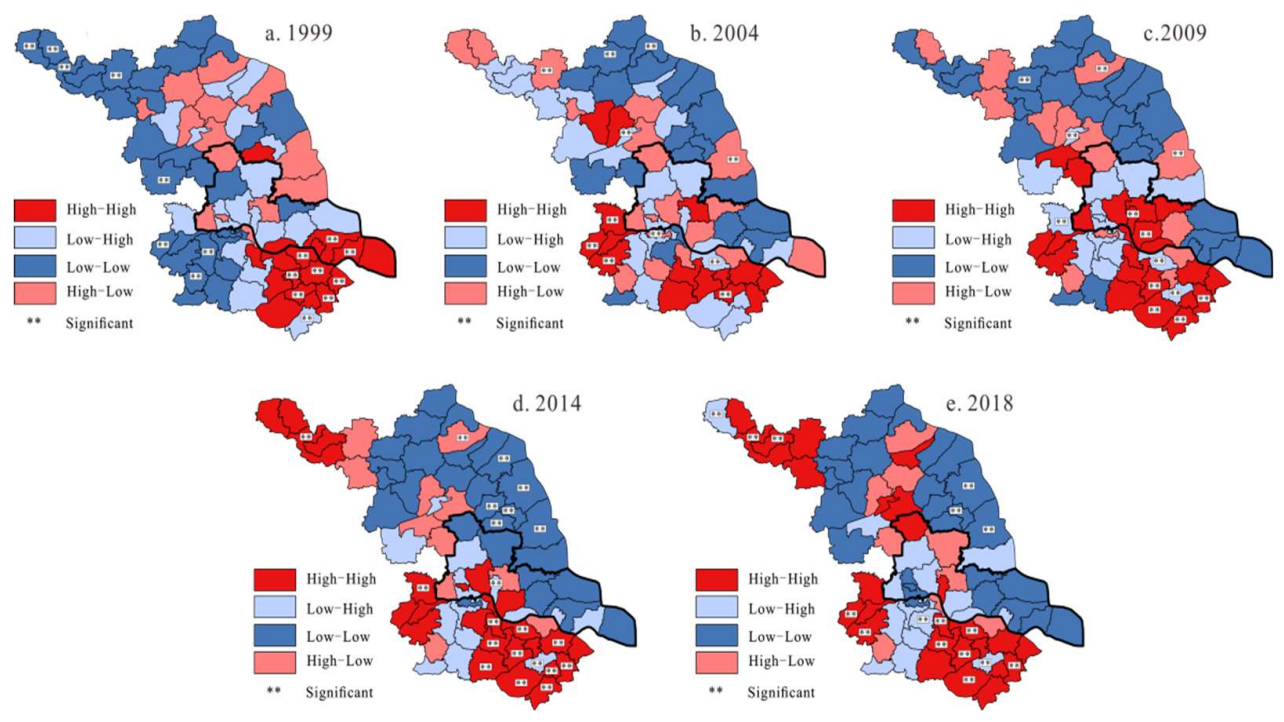

Figure 5 Spatial association pattern of regional agricultural eco-efficiency

\subsection{Spatial decomposition and growth pattern of agricultural eco-efficiency}

The growth coordination between agricultural eco-efficiency, PTE, and SE was identified, mapped, and categorized in terms of growth type. As shown in Figure 6, the spatial geomean pattern of PTE is generally consistent with agricultural eco-efficiency, where high values are found in the north, and low values are at the south. Regions with relatively low PTE geomean were distributed in Subei, the coastal regions of Suzhong, and parts of the Ningzhen Yang Hilly region. For SE, the geomean value for each county and district was higher than the PTE, indicating that SE contributed significantly in promoting agricultural eco-efficiency. The SE exhibited high south and low north spatial pattern. Areas with high SE were found mainly in Sunan, the inland regions of Suzhong, and Huai'an city of Subei, while low SE Regions were clustered in the coastal and northern regions of Subei, particularly in Yancheng city.

For the study period, areas with positive growth in TE, PTE, and SE accounted for $27.27 \%$ and were mainly situated in Xuzhou, Huai' an, Yangzhou, Nanjing, and Changzhou City. This suggests these regions' positive agricultural eco-efficiency growth had been accompanied by the synergistic growth in EC and TC. Areas with negative TE, negative PTE, and positive SE, accounted for $22.08 \%$ and were mainly distributed in the Subei region. Areas with this growth combination had their agricultural eco-efficiency growth dragged down by the lag in PTE growth. Areas with negative TE, PTE, and SE comprised about $25.97 \%$ and were concentrated in the coastal regions of Suzhong and Sunan and along the Yangtze River region. In these regions, the negative agricultural eco-efficiency was caused by the deterioration in PTE and SE. The other growth types were relatively marginal and are scattered throughout the entire province. 


\begin{tabular}{ccccccc}
\hline & \multicolumn{2}{c}{ Low Value } & \multicolumn{2}{c}{ Moderate Value } & \multicolumn{2}{c}{ High Value } \\
Type & Number & Proportion (\%) & Number & Proportion (\%) & Number & Proportion (\%) \\
\hline x1 & 24 & 31.17 & 34 & 44.16 & 19 & 24.68 \\
x2 & 19 & 24.68 & 35 & 45.45 & 23 & 29.87 \\
x3 & 16 & 20.78 & 24 & 31.17 & 37 & 48.05 \\
x4 & 14 & 18.18 & 26 & 33.77 & 37 & 48.05 \\
x5 & 9 & 11.69 & 15 & 19.48 & 53 & 68.83 \\
x6 & 28 & 36.36 & 30 & 38.96 & 19 & 24.68 \\
x7 & 11 & 14.29 & 12 & 15.58 & 54 & 70.13 \\
x8 & 15 & 19.48 & 20 & 25.97 & 42 & 54.55 \\
z1 & 9 & 11.69 & 16 & 20.78 & 52 & 67.53 \\
\hline
\end{tabular}

Figure 6 The geomean and growth type of between agricultural eco-efficiency, PTE, and SE

\subsection{The sources for agricultural eco-efficiency loss in Jiangsu province}

For the non-effective DEA unit, the results show that the input-output allocation had not reached the optimal level. The redundancy analysis of input factors can identify the reasons for agricultural eco-efficiency loss in Jiangsu province and clarify the potential for increasing agricultural eco-efficiency. According to the SBM model, when $\mathrm{p}^{*}<1, \mathrm{~s}^{-}, \mathrm{s}^{\mathrm{g}}$, and $\mathrm{s}^{\mathrm{b}}$ can reflect the redundancy of agricultural eco-efficiency. To calculate the input-output redundancy rate in each county or district, the redundancy value of each input indicator and undesirable output indicator is divide by each input indicator and undesirable output indicator. For analysis, the input-output redundancy rate can be subdivided into three categories: low value $(0-20 \%)$, moderate value $(20-35 \%)$, and high value ( $>35 \%)$. The number and proportion of counties and districts for each indicator are shown in Table 3.

Table 3 The number and proportion of counties and districts at different intervals of indicators

As shown in Table 2, the loss of agricultural eco-efficiency in most counties and districts resulted from the excessive use of pesticide (x5), chemical fertilizer (x7), diesel (x8),
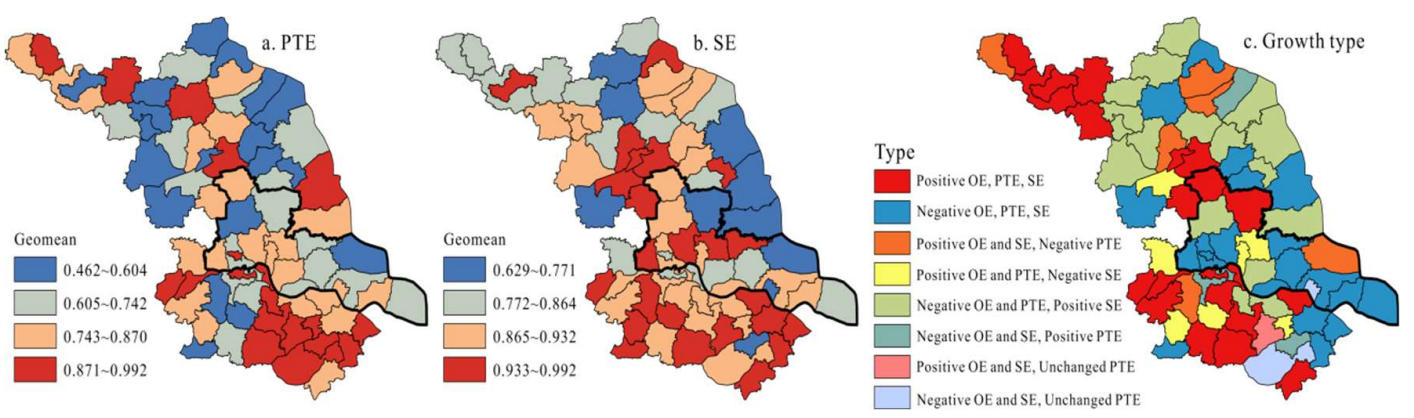
labor (x3), land (x4), and agricultural carbon emissions (z1). In particular, the number of counties and districts with high values of pesticide (x5) and chemical fertilizer (x7) use was 53 and 54 , equivalent to $68.83 \%$ and $70.13 \%$. This means that about $68 \%$ of all counties and districts should reduce their agricultural pesticide and chemical fertilizer usage by at least $35 \%$. Similar conclusions are applicable for $x 8, x 3$, and $x 4$. In terms of the undesirable output (z1), 67.53\% of all counties and districts were found to have high input-output redundancy rates. Since part of agricultural carbon emissions result from chemical fertilizer (x5), pesticide (x7), diesel (x8), and arable land (x4), excessive usage of agricultural chemicals and extensive farming techniques are significant factors influencing the agricultural eco-efficiency. Similarly, x2 exerted considerable effects on agricultural eco-efficiency, while x6 (32) and x1 (28) only had minimal effect.

ArcGIS10.5 was then used to visualize the spatial difference of the reducible proportion for the different indicators. As shown in Figure 7, areas with high reducible proportions were mainly situated in Subei, Suzhong, and the Ningzhen Yang Hilly region, while the majority of low reducible proportion counties and districts were clustered in the Taihu plain. For chemical fertilizer (x7), the spatial pattern exhibited distinct south low and north high distribution. Similar spatial pattern could be drawn for $x 3, x 4, x 5$, and $x 8$. Due to improvements in agricultural mechanization and the growth of production technology, the improvement capabilities for $\mathrm{x} 1, \mathrm{x} 2$, and $\mathrm{x} 6$ were limited in most counties and districts.
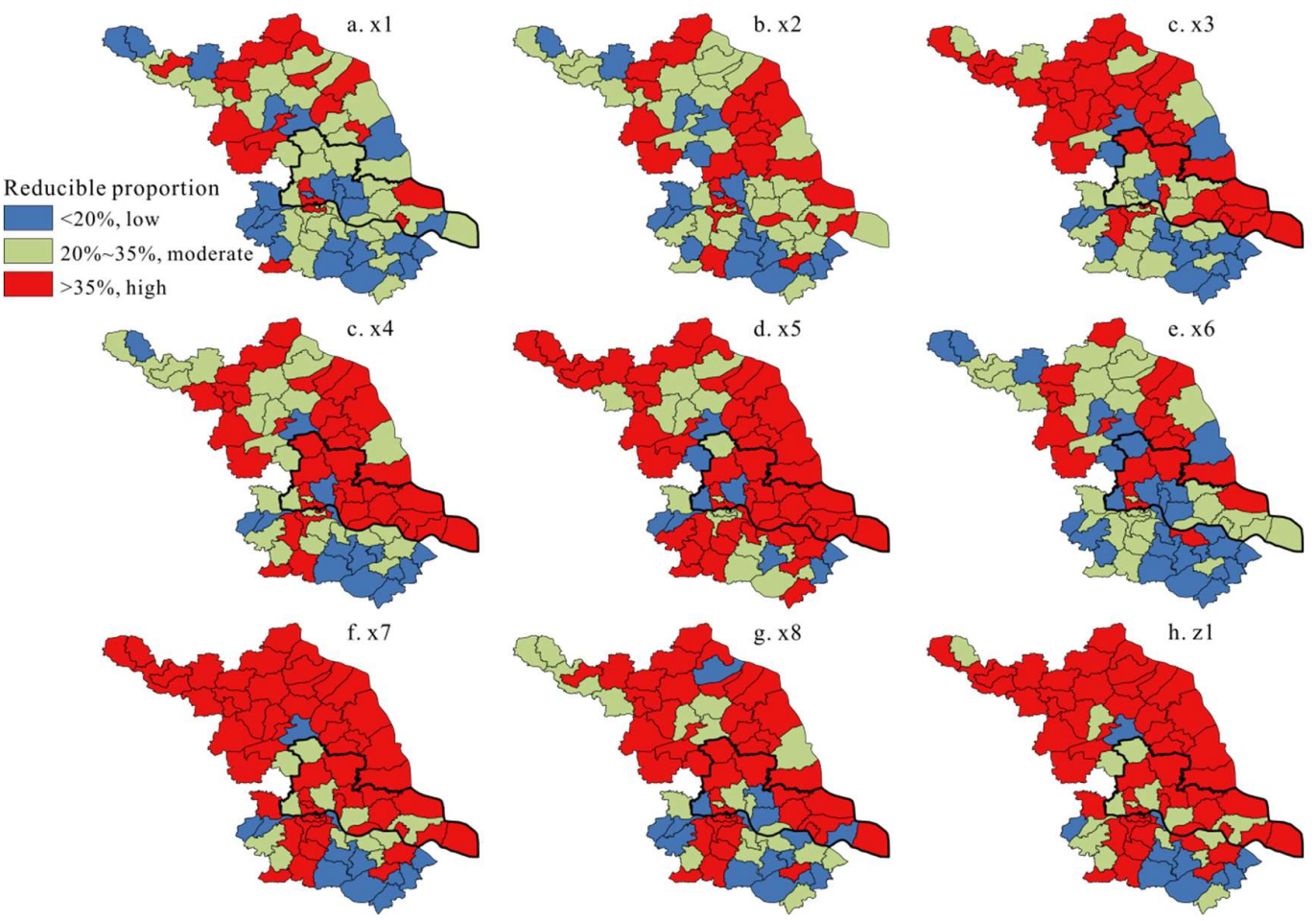

Figure 7 The improvement potential for agricultural ecological efficiency in Jiangsu province

\section{Discussion}

The changing trends in agricultural eco-efficiency, PTE, and SE show that the slow growth of agricultural eco-efficiency in Jiangsu province for the past twenty years has 
been caused by the negative growth in pure technical efficiency, resulting in the low-level conversion rate of green technology and unreasonable allocation of resources. Scale efficiency played an important role in promoting Jiangsu's agricultural eco-efficiency. With the accelerating land-intensive degree in Jiangsu province, the scale effect of the labor, machinery, and chemical fertilizer inputs were brought into full play. This suggests that more attention should be given towards agricultural technological innovation and to the rational resource allocation to minimize the reduction of agricultural eco-efficiency caused by the lag in pure technology efficiency.

Jiangsu's agricultural eco-efficiency suddenly dipped in 2003, related to the rise of the real estate industry that caused the expropriation of many agricultural lands. Since 2004, agricultural eco-efficiency entered a new stage of rapid development, which resulted from a series of policies issued by the Chinese government in support of agriculture. Jiangsu was also able to adjust its agricultural structure and implement relevant fiscal policies to benefit farm operations. These actions contributed towards promoting the development of modern agriculture with high yield, high efficiency, ecology, and safety in Jiangsu province.

The spatio-temporal patterns in geomean values, variation coefficients, and growth types indicate that the high south and low north spatial configuration is relatively constant and cannot easily be changed. Besides, the significantly increasing global Moran's I values indicate that the spatial clustering in agricultural eco-efficiency is intensifying. The results also show the spatial pattern of local High-High and Low-Low clusters became more spatially concentrated. These results suggest that the spatial evolution pattern of agricultural eco-efficiency has a relatively stable spatial dependence due to limitations in environmental conditions and agricultural production technology.

Given the dominance of planting in the agricultural sector in Jiangsu, the proportion of planting output over the total agricultural output was over $50 \%$ during 1999-2018. During the planting production process, large amounts of chemical fertilizer, pesticide, agricultural film, and other direct and indirect material input are expended, which consumes energy and causes environmental damage through greenhouse gas emissions, soil structure deterioration, and water quality degradation [5]. Excessive chemical fertilizer and pesticide use have been identified as primary pollution sources in agricultural production [47].

At the same time, the spatial difference in the reducible proportion of input factors was found to be closely related to the regional economic disparity in Jiangsu. Sunan has a developed economy and a strong purchasing capacity for agricultural materials. Suzhong and Subei have been relatively rich in labor and land resources, and agriculture accounted for a large proportion of the local economy. The redundancy in various production factors has been relatively high due to their extensive agricultural production mode.

Given the low agricultural eco-efficiency, Jiangsu province needs to continue transforming its agricultural operation mode as a strategic focus towards green agricultural development. The province also needs to accelerate in upgrading its agricultural technical level, improve the allocation efficiency of agricultural production factors, and promote the transformation of agricultural operation from high investment extensive type to intensive ecological type. All counties and districts should capitalize on their regional advantages to develop their agricultural sector according to local conditions. Due to redundancies in the current input factor structure, farmer education and training should be strengthened, and incentive-based policies should be adopted that would change the traditional production mode and reduce the dependence on chemical fertilizer and pesticide. The government should encourage adjustments in the agricultural-industrial structure to enhance the absorption capacity of enterprises in integrating the rural labor force. The government should also increase the integration of rural arable 
land and infrastructure construction and promote agricultural industrialization and mechanization to improve land utilization efficiency.

There are several limitations in this study. The influencing factors of agricultural eco-efficiency were based on the analysis of input redundancy. However, eco-efficiency may also be influenced by socioeconomic and natural and ecological variables, such as urbanization rate, terrain, and the fragmentation degree of cultivated land. Future studies need to further explore and analyze how these factors may affect agricultural eco-efficiency.

\section{Conclusion}

This paper evaluated the agricultural eco-efficiency of 77 counties and districts in Jiangsu province from 1999 to 2018 using the non-radial and non-angular SBM model and analyzed its spatio-temporal evolution pattern and underlying reasons. The main conclusions are as follows:

The overall agricultural eco-efficiency and its decomposition terms of pure technology efficiency and scale efficiency exhibited a downward fluctuation trend from 1999 to 2018. The improvement of agricultural eco-efficiency in Jiangsu mainly depended on promoting scale efficiency, while pure technology efficiency made secondary contributions. The regional inequality in agricultural eco-efficiency among counties and districts has been widening, exhibiting strong positive spatial association. Thus, it is necessary to strengthen the research and development of agricultural production technology to improve pure technical efficiency.

The agricultural eco-efficiency in Jiangsu exhibited a "high south and low north" spatial pattern. High-level agricultural eco-efficiency areas could be found on the Taihu Plain in Sunan, while low-level agricultural eco-efficiency areas were distributed in the rugged hills and bordering counties and districts of Yancheng, Changzhou, Huai'an, Suqian, Xuzhou, and Lianyungang city. The spatial association pattern of agricultural eco-efficiency presented a spatial locking effect. The High-High areas had increasingly concentrated in the Suzhou-Wuxi-Changzhou region, while the Low-Low areas were mainly located in the coastal regions of Subei and Suzhong. The High-Low and Low-High areas were marginal in number and scattered all over the region. Moreover, the spatial pattern of PTE and SE demonstrated a "north high and south low" distribution.

Excessive redundant use of pesticide, chemical fertilizer, agricultural diesel, labor, land, and agricultural carbon emission were the major factors influencing agricultural eco-efficiency in Jiangsu. Irrigation also significantly impacted agricultural eco-efficiency, while mechanical power and the agricultural film had minimal effect. The majority of counties and districts in Subei, Suzhong, and the Ningzhen Yang Hilly region should significantly reduce their use and dependence on chemical fertilizer, pesticide, chemical fertilizer, agricultural diesel, labor, and land.

Acknowledgments This work is funded by Humanities and Social Science Foundation of Ministry of Education of China [20YJCZH080] and the Jiangsu Provincial Social Science Foundation [20SHD009].

\section{References}

1. Liu, Y.; Zou, L.; Wang, Y. Spatial-temporal characteristics and influencing factors of agricultural eco-efficiency in China in recent 40 years. Land Use Policy. 2020, 97, 104794.

2. Zou, L.; Liu, Y.; Wang, Y.; Hu, X. Assessment and analysis of agricultural non-point source pollution loads in China: 1978-2017. Journal of Environmental Management. 2020, 263, 110400. 
3. Du, H. Z. The research on countermeasures of green agricultural development in Jiangsu province, Asian Agricultural Research. 2010, 2, 1-8.

4. Tian, Y.; Zhang, J.B.; He, Y.Y. Research on spatial-temporal characteristics and driving factor of agricultural carbon emissions in China. Journal of Integrative Agriculture. 2014, 13, 1393-1403.

5. Xiong, C.; Chen, S.; Xu, L. Driving factors analysis of agricultural carbon emissions based on extended STIRPAT model of Jiangsu Province, China. Growth and Change. 2020. doi:10.1111/grow.12384.

6. Liu, Q.P.; Giesy, J.P.; Li, Z.H. Spatio-temporal distributions and environmental safety threshold of cropland fertilization of Jiangsu Province, China. Advanced Materials Research . 2014, 962-965, 2110-2115.

7. Guo, J.X.; Hu, X.Y.; Ga, L.M.; Xie, K.L.; Ling, N.; Shen, Q.R.; Hu, S.J.; Guo, S.W. The rice production practices of high yield and high nitrogen use efficiency in Jiangsu, China. Scientific Reports. 2016, 7, 2101.

8. Huang, J.Y.; Xiong, R.N.; Fang, L.; Li, T.L.; Shen, W.S. Estimation of interannual trends of ammonia emissions from agriculture in Jiangsu province from 2000 to 2017. Atmospheric and Oceanic Science Letters. 2020, 13, 268-273.

9. Huang, S.S.; Liao, Q.L.; Hua, M.; Wu, X.M.; Bi, K.S.; Yan, C.Y.; Chen, X.Y.; Zhang, X.Y. Survey of heavy metal pollution and assessment of agricultural soil in Yangzhong district, Jiangsu province, China. Chemosphere. 2007, 67, 21482155.

10. Zhang, X.J.; Wu, M.; Yao, H.Y.; Yang, Y.M.; Cui, M.J.; Tu, Z.B.; Stallones, L.; Xiang, H.Y. Pesticide poisoning and neurobehavioral function among farm workers in Jiangsu, People's Republic of China. Cortex. 2016, 74, 396-404.

11. Pretty, J. Agricultural sustainability: concepts, principles and evidence. Philosophical Transactions of the Royal Society B: Biological Sciences. 2008, 363, 447-465.

12. Bonfiglio, A.; Arzeni, A.; Bodini, A. Assessing eco-efficiency of arable farms in rural areas. Agricultural Systems. 2017, 151, 114-125.

13. Kuosmanen, T. Measurement and analysis of eco-efficiency: An economist's perspective. Journal of Industrial Ecology. 2005, 9, 15-18.

14. Camarero, M.; Castillo, J.; Picazo-Tadeo, A. J.; Tamarit, C. Eco-efficiency and convergence in OECD countries. Environmental and Resource Economics. 2012, 55, 87-106.

15. Georgopoulou, A.; Angelis-Dimakis, A.; Arampatzis, G.; Assimacopoulos, D. Improving the eco-efficiency of an agricultural water use system. Desalination and Water Treatment. 2015, 57, 11484-11493.

16. Keating, B.A.; Carberry, P.S.; Bindraban, P.S.; Asseng, S.; Meinke, H.; Dixon, J. Eco-efficient agriculture: Concepts, challenges, and opportunities. Crop Science. 2010, 50, S-109.

17. Gancone, A.; Pubule, J.; Rosa, M.; Blumberga, D. Evaluation of agriculture eco-efficiency in Latvia. Energy Procedia. 2017, 128, 309-315.

18. Xu, Y.L.; Li, Z.J;; Wang, L. Temporal-spatial differences in and influencing factors of agricultural eco-efficiency in Shandong province, China. Ciência Rural. 2020, 50, e20190818. 
19. Rosano-Peña, C.; Almeida, C.A.R. de.; Rodrigues, E.C.C.; Serrano, A.L.M. Spatial dependency of eco-efficiency of agriculture in São Paulo. Brazilian Business Review. 2020, 17, 328-343.

20. Xiang, H.; Wang, Y.H.; Huang, Q.Q.; Yang, Q.Y. How much is the eco-efficiency of agricultural production in west China? Evidence from the village level data. International Journal of Environmental Research and Public Health. 2020, 17, 4049 .

21. Picazo-Tadeo, A.J.; Gómez-Limón, J.A.; Reig-Martínez, E. Assessing farming eco-efficiency: A data envelopment analysis approach. Journal of Environmental Management. 2011, 92, 1154-1164.

22. Barnes, A.P.; Thomson, S.G. Measuring progress towards sustainable intensification: How far can secondary data go? Ecological Indicators. 2014, 36, 213-220.

23. Victor, M.; Margarita, R.; Pedro, M. Economic-environmental efficiency of European agriculture-a generalized maximum entropy approach. Agricultural Economics Zemědělská Ekonomika. 2018, 64, 423-435.

24. Czyżewski, B.; Matuszczak, A.; Grzelak, A.; Guth, M.; Majchrzak, A. Environmental sustainable value in agriculture revisited: How does common agricultural policy contribute to eco-efficiency? Sustainability Science. 2020, doi:10.1007/s11625-020-00834-6.

25. Chen, C.M. Evaluating eco-efficiency with data envelopment analysis: An analytical reexamination. Annals of Operations Research. 2014, 214, 49-71.

26. Huang, J.; Xia, J.; Yu, Y.; Zhang, N. Composite eco-efficiency indicators for China based on data envelopment analysis. Ecological Indicators. 2018, 85, 674-697.

27. Yu, Y.; Zhang, Y.; Miao, X. Impacts of dynamic agglomeration externalities on eco-efficiency: Empirical evidence from China. International Journal of Environmental Research and Public Health. 2018, 15, 2304.

28. Tone, K. A slacks-based measure of efficiency in data envelopment analysis. European Journal of Operational Research. 2001, 130, 498-509.

29. Tone, K. Dealing with undesirable outputs in DEA: A slacks-based measure (SBM) approach. North American Productivity Workshop. 2004, 44-45.

30. Peng, H.S.; Zhang, J.H.; Lu, L.; Tang, G.; Yan, B.; Xiao, X.; Han, Y. Eco-efficiency and its determinants at a tourism destination: A case study of Huangshan National Park, China. Tourism Management. 2017, 60, 201-211.

31. Tobler, W.R. A computer movie simulating urban growth in the Detroit region. Economic Geography. 1970, 46, 234-240.

32. Anselin, L. Spatial effects in econometric practice in environmental and resource economics. American Journal of Agricultural Economics. 2001, 83, 705-710.

33. Guan, W.; Xu, S. Study of spatial patterns and spatial effects of energy eco-efficiency in China. Journal of Geographical Sciences. 2016, 26, 1362-1376.

34. Wang, Z.; Sun, Y.; Yuan, Z.; Wang, B. Does energy efficiency have a spatial spill-over effect in China? Evidence from provincial-level data. Journal of Cleaner Production. 2019, 241, 118258. 
35. Zhou, Y.; Kong, Y.; Zhang, T. The spatial and temporal evolution of provincial eco-efficiency in China based on SBM modified three-stage data envelopment analysis. Environmental Science and Pollution Research International. 2020, $27,8557-8569$.

36. Wu, C.; Chen, B.; Huang, X.; Dennis Wei, Y.H. Effect of land-use change and optimization on the ecosystem service values of Jiangsu province, China. Ecological Indicators. 2020, 117, 106507.

37. Hu, L.X.; Zhang, X.H.; Zhou, Y.H. Farm size and fertilizer sustainable use: An empirical study in Jiangsu, China. Journal of Integrative Agriculture. 2019, 18, 2898-2909.

38. Xu, K.; Bossink, B.; Chen, Q. Efficiency evaluation of regional Sustainable innovation in China: A slack-based measure (SBM) model with undesirable outputs. Sustainability. 2019, 12, 31.

39. Guo, L.; Na, S.; Tan, X.; Gui, P.; Liu, C. Evolution of the efficiency of nationwide commercial banks in China based on an SBM-Undesirable model and DEA window analysis. Mathematical Problems in Engineering. 2020, 1-12. doi:10.1155/2020/4682790.

40. Cheng, G. Data envelopment analysis: Methods and MaxDEA software. Intellectual Property Publishing House Co. Ltd. Beijing, 2014,.

41. Zhou, L.J.; Zhu, S.Y. Research on the efficiency of Chinese commercial banks based on undesirable output and Super-SBM DEA model. Journal of Mathematical Finance. 2017, 7, 102-120.

42. Kim, T.; Dall'erba, S. Spatio-temporal association of fossil fuel $\mathrm{CO}_{2}$ emissions from crop production across US counties. Agriculture, Ecosystems \& Environment. 2014, 183, 69-77.

43. Fan, Q.Y.; Yang, S.; Liu, S.B. Asymmetrically spatial effects of urban scale and agglomeration on haze pollution in China. International Journal of Environmental Research and Public Health. 2019, 16, 4936.

44. Anselin, L. Local indicators of spatial association-LISA. Geographic Analysis. 1995, 27, 93-115.

45. Zhang, Y.; Xu, J.H.; Zhuang, P.J. The spatial relationship of tourist distribution in Chinese cities. Tourism Geographies. 2011, 13, 75-90.

46. Xiong, C.; Yang, D.; Huo, J. Spatial-temporal characteristics and LMDI-based impact factor decomposition of agricultural carbon emissions in Hotan prefecture, China. Sustainability. 2016, 8, 1-14.

47. Chen, J.; Ma, G.S. Study on environmental pollution and control countermeasures of agricultural and rural areas in Jiangsu province. Atlantis Press. 2018, https://doi.org/10.2991/iceep-18.2018.288. 